\title{
Access To Higher Education For National Development In Nigeria: Distance Education To The Rescue
}

\author{
Tewo V. Bakare, Ph.D., University of Lagos, Nigeria
}

\begin{abstract}
The paper examined the place of Distance Education (DE) as a method of Adult Education in Nigeria and its contribution to national development. The paper discussed DE practice and challenges in some African countries and related this to the Nigerian situation. The paper further noted the challenge of the national admission body for regular tertiary institutions with reconciling the ratio of applicants to those admitted. Incidentally, DE, which is originally a form of Adult Education, is fast becoming a replacement for regular higher education. The implication of this on Adult Education practice in Nigeria is that the changes in the demographics of participants in DE, along with other challenges, affect the essence of Adult Education provision, access and its conduct. The paper analyzed the concept of DE and noted that distance education is currently used to replace, instead of support mainstream education in Nigeria by eroding the more desirable non-formal approach. The paper agrees that DE can be used as a tool, per excellence, for human and national development, if practiced in its proper context, and attracts the desired target candidates. Several suggestions were proffered for better conduct of DE, including the use of awareness campaigns to attract the right candidates into DE programs as well as better provision of access to regular education for the youth to stem their influx into DE. The discourse has great implications for lifelong learning, access, national development and adult education practice in Nigeria and globally.
\end{abstract}

Keywords: Adult Education Method; Distance Education; Access; National Development; Nigeria; Higher Education

\section{INTRODUCTION}

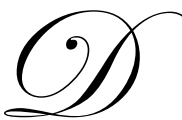

istance Education (DE) is arguably one of the more prolific methods of adult education as noted by the influx of candidates into its programs. Also, in more recent times, there has been a renewed impetus by Nigeria, in a bid to satisfy the large and quickly expanding clientele for higher education, to resort to DE as a tool to redeem the collective pledge made on September $29^{\text {th }}$ of 2000 at the Abuja Declaration of the 2001- 2010 Decade of Distance Education in Nigeria. The highlight of the pledge was the solemn resolution to 'adopt distance education as a desirable and inevitable mode for providing access to all and achieving equitable representation by taking the distance out of education.' However, in a country where the demand for higher education far surpasses the supply, it has proved to be more challenging for DE to contribute optimally to the openness of educational provision in the country. Nigeria's dilemma was compounded by the enthusiasm to adhere to the policy of education for all (EFA) and universal right to education. The free and compulsory Universal Primary Education (UPE) that began in 1976 and the subsequent Universal Basic Education (UBE) initiative of 1999 have now released a huge number of potential candidates into the tertiary system. Unfortunately, the nation seems to be ill prepared for the increased demand for higher education by this younger generation who now find their way into DE programs, thereby jeopardizing access for deserving adult learners. If the demand for higher education continues to rise at the present pace, regular provision for admission into higher education will be ineffective in handling the influx, it is therefore necessary to see if DE is capable of fulfilling its mandate to step in and ensure equity and access in the effort to promote a learning society that will contribute more effectively to national development. 
Nigeria has a comparable DE system to many other African nations but they all share similar challenges. According to COL (2005), Kenya's challenges include funding, inclusivity, internationalizing DE, access as well as ICT provision, along with quality assurance, among others. Botswana talks of policy and access and even suggests that DE be more of a central component rather than marginal. In Lesotho, they talk of government support and the need to recruit qualified and competent distance education practitioners. Namibia sees DE as a means of achieving her vision 2030 for social and economic development agenda and talks of advocacy to sensitize management about the needs of DE provision. Tanzania's Open University equally has challenges in its conduct (Nekongo-Nielsen et al, 2011). Above all, they all talk of ICT and the quality of delivery of DE. They collectively struggle with the lack of government-driven legitimization of DE, which leads to the lack of understanding of what DE is, and what it entails as a method of accessing further education opportunities, along with a nationally pervasive resistant and/or negative attitude and mindset towards DE. Nigeria faces all of these challenges also, but rather more peculiar, is the level of influx of a younger generation into alternative education to fill a gap. Even so, the potential of DE to improve access to higher education is yet to be fully explored and exploited by the requisite audience as a panacea for boosting human and national development. DE becomes even more germane to developmental aspirations in view of the fact that majority of Nigerians still live in the rural areas, and often below the poverty level, and therefore have limited access to the higher education they deserve. Many have also had to begin work earlier in their lives in order to meet social and family obligations; there is again the gender issue whereby women are more affected in this deprivation. Adding to the problem is the issue of proximity to the location of the higher institutions as well as other challenges like physical disability, and quite often, financial setbacks. All these, while stamping the clientele as adults on one hand, also on the other hand contribute to their inability to fully participate in national development efforts because of their inability to achieve their full educational potential. Many are also obviously unaware of the option of alternative means of higher education that will not involve their presence.

\section{THE CONCEPT OF DISTANCE EDUCATION}

Distance Education (DE) is the totality of all education that is characterized by physical separation (in time and/or distance) between the individual learner and the teacher (unlike in the traditional face-to-face classroom setting); where content is then delivered through alternative media like print and Information Communication Technology (ICT). Kaufman et al (2001) see DE as a means of delivery of useful learning opportunities at convenient time and place. Jegede (2003) calls DE the education that is provided by a mode other than the conventional face-to-face method, but whose goals are similar to and just as noble as those of on-campus, full time face-to-face education. The Association for the development of Education in Africa (ADEA) Working Group on Distance Education and Open Learning (2002) identify the characteristics of DE as including:

- Institutional accreditation (where an institution or agency certifies the learning);

- Use of a variety of media for instructional delivery;

- $\quad$ Provision of two-way communication to ensure tutor-learner and learner-learner interaction, and

- The option of face-to-face meetings for tutorials for learner-learner interaction, laboratory or practice session or library study.

All these parameters are strictly adhered to in the practice. Distance education is seen as synonymous with adult education. It is typically student-centered and was originally intended to extend education to those who need it for various reasons and cannot come to an institution, but also serves as a means of bridging the gap between the unmet demand and supply of tertiary educational opportunities, as well as to help provide accessible, equitable, qualitative and democratic education, according to the government. Moodley (2002) also observed that previous DE candidates in earlier times included adults who sought advanced education at home, on the job or even the military, but added that nowadays, anyone is a potential distance learner - an idea that will certainly influence the conduct of DE.

In terms of development, DE can serve as a social institution whose graduates become better equipped as professionals and add value to society. This is because higher education through DE as key to a skilled work force, contributes to a vibrant work force and development; in addition, a nation with an unskilled labour force has fewer development options. It is expected that the adult's newly acquired knowledge and more marketable skills elevate the level of understanding, boost employability/job mobility and make for better participation in the design and 
implementation of strategies that help solve communities' problems, while raising the collective standard of living. It will further help promote the application of technology, increase prosperity and encourage progress. Also, reaching the remote areas with $\mathrm{DE}$ helps to spread development evenly and to achieve rapid development, while simultaneously helping to reach the EFA goals more equitably, faster and with justice for all. All these become more relevant with the realization that we are competing at the global level and a knowledge-based economy requires skills acquired at the tertiary level (Boshier, 2002). Therefore DE can be used as a strategy to develop the necessary human resources while helping the university community achieve its extension education obligations by reaching out to the hitherto unreached, and packaging the educational offering to reach remote locations instead of requiring physical presence at their institutions. One of the major purposes of using DE is to help increase access to higher education for individuals who cannot be physically present. The parallel to this is the formal, residential or contact-based university program that is supposed to attract young initial entrants, fresh from the completion of their General Certificate of Education (GCE O'level) diploma. Unfortunately, because regular university education may not fit into the lifestyle of the learning adult, many have given up on higher education and thereby reduced the level of their possible contribution to developmental efforts in the nation.

\section{DE AND ADULT EDUCATION}

DE was originally intended and suited for adult learners as a more flexible alternative (of comparative standards and quality) to the conventional option in the provision of access to university education to qualified candidates. DE is best suited for the more mature learner who has the capacity to assess his circumstances, make life choices, thus, as a self-directing individual, benefits more from distance education as an active discoverer and constructor of his own learning. According to the American Council on Education (cited in Pityana (2004):

'the process of DE as different from the non-traditional study is more of an attitude than a system. This attitude puts the student first and the institution second, concentrates more on the former's needs than the latter's convenience, encourages diversity of individual opportunity rather than uniform prescription, while de-emphasizing time and space....'.

These attributes make DE more suited to the adult whose maturity will enable him learn independently, think, reflect, make informed choices and gain more from unsupervised learning. Moore and Kearsely, cited in Jensen (1998) agree that DE is meant more for adult learners (aged 25-50); especially because adult learners possess certain definitive qualities that set them apart. Adult learning circumstances are deemed to be different from that of children. This is, according to Knowles (1984) because of certain characteristics that set them apart from the child learner - they learn for immediate use, they have life experience that must be incorporated into the teaching/learning experience, are problem centered, self-directing and internally motivated, among others. All of these, coupled with the expectation that they are full time workers, with family and other social responsibilities, and that they may have been non-completers at different stages of their education, make them ripe candidates for DE. In fact, DE was originally tailored to fit the adult learners' circumstances. The fact that they may not be able to leave their full time job or family responsibilities, but are otherwise self-directing enough to fit education into their life style shows that they still appreciate the importance of education as a lifelong endeavour.

Other elements of DE that make it most suitable for adult learning and more student-centered include:

- It is considerate of the adult's other responsibilities and so allows for a more self-controlled pace of learning, convenient location, time and other concessions, often not bounded by conventional classroom settings or teacher's presence and so helps to bypass the rigidity of formal education;

- It allows the learner to assume a higher level of responsibility for his own learning as well as its management and be more active in the choice of his goals, thereby enriching his learning potential;

- It also allows more emphasis on and the learner's involvement in the process of learning ;

- It helps to enrich the learner's experience outside the classroom and personalize the learning strategy, making it more flexible while encouraging the use of technology, and

- It may also encourage student/student interaction, apart from the expected teacher/learner; it promotes self learning, peer tutoring, team work and cooperation, thereby ensuring social interaction, which will, in turn, contribute to national development (Salmon, 2000). 
DE however also has some setbacks; some of the disadvantages include:

- Human beings are basically social animals and will often prefer one-on-one (face to face) interaction which may be a setback to the understanding of the conduct of DE;

- $\quad$ The feedback may be delayed and, since adults are usually anxious to track their own progress, this may act as a deterrent to their full learning potential;

- $\quad$ The ICT ingredients are often lacking, and computer illiteracy may also be a factor, not to talk of the lack of access to the necessary ICT infrastructure, and

- $\quad$ Because it lacks the immediate human touch and interaction, the encouragement may not be spontaneous and many life skills are also difficult to learn in absentia or through the computer, among others.

\section{DE AS A TOOL FOR NATION BUILDING IN NIGERIA}

There is the need for Nigeria, with her over 140 million people (NPC, 2007) - and counting; with the continuing demand for education at all levels, to meet the target of education for all, especially faced with the challenge of sourcing for effective and cost-beneficial alternative modes of educational delivery. This has led to the establishment of the different forms of DE in Nigeria. Unfortunately, present circumstances indicate a more general preoccupation with creating more private Universities in order to plug the gap between admission into regular higher institutions and DE institutions, rather than giving the deserved credence to DE; thus DE hardly enjoys its due recognition yet in terms of providing alternative access to higher education in Nigeria. The most palpable area in which DE contributes to nation building remains in the area of Workers' Education.

Many have spoken about the partnership between distance education and development and there is a consensus as to the efficacy of this form of adult education as a tool for national development. DE serves as a vehicle for getting an education that will be crucial in making learners active participants in the development process (Amuako, 2009; Omolewa, 2001; Marope, 2005, Ukertor, 2010). According to Pityana (2004), Higher education is an important element in the formation of character, in providing skills, nurturing a reflective quality and the capacity to think and formulate thoughts independently and evaluate situations critically. This will undoubtedly enrich the learner's ability to contribute to national developmental efforts. DE is expected to contribute to the building of mentally, physically, emotionally and psychologically stable individuals who will contribute to sustainable human development and ultimately help achieve the MDG and EFA goals of reducing poverty and social inequalities as well as unemployment. It will further contribute to improving the quality of life and help to increase participation in national development efforts.

\section{THE CURRENT STATUS OF DE IN NIGERIA}

Distance education is conducted in several ways in Nigeria - largely through Correspondence Education, the Open University system and the Distance Learning Institutes. All these indicate the different modes of achieving transformational education. The key DE institutions are epitomized by the Nigerian Open University (NOUN) in Lagos, the Distance Learning Institute domiciled in the University of Lagos and what was known as the Correspondence College.

Several Universities in Nigeria were built on the modalities of distance education (Aderinoye and Ojokheta (2004). Examples include correspondence programs in Ahmadu Bello University (the Correspondence and Teachers' In-Service Programs, TISEP), University of Lagos (Correspondence and Open Studies Unit, COSU), the National Teacher's Institute (the first independent institution dedicated solely to distance education), as well as the University of Ibadan's External Study Program, (ESP) for teachers on the job, among others and they all awarded degrees and diplomas in teacher education. Virtually all Nigerian Universities today have Sandwich and other parttime correspondence programs. Nigeria certainly appreciates the importance of higher education as reflected in its inclusion in the National Policy on Education. According to the NPE (2004:45), Open and Distance Learning is included with the aim of:

- $\quad$ Providing access to quality education and equity in educational opportunities for those who otherwise have been denied; 
- $\quad$ Meeting special needs of employers by mounting special certification courses for their employees at their work place;

- $\quad$ Encouraging internalization, especially of tertiary education curricula, and

- Ameliorating the effect of internal and external brain drain in tertiary institutions by utilizing Nigerian experts as teachers, regardless of their location of places of work.

The underlining tone of the second and third statements suggest an audience of adult and full time workers as the target for DE rather than those transitioning from secondary education to the university system. Previous educational provision and policies in Nigeria seemed to have excluded a large number of the populace and prevented them from contributing to development. Prior to the development of a viable higher education system in Nigeria, and before independence, the distance education system, especially through correspondence education, was heavily relied upon and served as the pioneer method of education for the educated elites at the time. These recipients later formed the core of administrators and educators who formulated and implemented policies, planning and other national development initiatives.

Nigeria has the largest University system in sub-sahara Africa (although, South Africa's tertiary enrolments are higher); unfortunately, Nigeria's university density remains one of the lowest in the world (Okunade, 2011). Nigeria has 103 universities (27 Federal, 35 States and 41 Private) all enrolling more than a combined total of over 400, 000 students (NUC, 2009). The rate at which people flood to higher education in Nigeria shows the interest of many to further their education. However, the country faces its own challenges in satisfying this unmet demand for higher education. Going by the records of the nation's central admission institution - the Joint Admission and Matriculations Board (JAMB), there is an imbalance between the number of applicants and the admission ratio (see tables 1 and 2). The process of higher education in Nigeria presently seems ill equipped to handle the influx of thousands of hopefuls every year as indicated by the table:

Table 1: Enrolment growth in Nigerian Universities between 1999 - 2009

\begin{tabular}{|c|c|c|c|c|}
\hline $\begin{array}{c}\text { Academic } \\
\text { Session }\end{array}$ & No of Applicants & No. Admitted & \% Admitted & $\begin{array}{c}\text { No of Unplaced } \\
\text { Applicants }\end{array}$ \\
\hline $1999 / 2000$ & 418,292 & 64,368 & 15.39 & 353,924 \\
\hline $2000 / 2001$ & 416,381 & 45,766 & 10.99 & 370,615 \\
\hline $2001 / 2002$ & 714,548 & 90,769 & 12.7 & 623,779 \\
\hline $2002 / 2003$ & 994,380 & 51,845 & 5.21 & 942,535 \\
\hline $2003 / 2004$ & $1,046,950$ & 105,157 & 10.04 & 941,793 \\
\hline $2004 / 2005$ & 841,878 & 122,492 & 14.54 & 719,386 \\
\hline $2005 / 2006$ & 916,371 & 65,609 & 7.16 & 850,762 \\
\hline $2006 / 2007$ & 803,472 & 123,626 & 15 & 679,846 \\
\hline $2007 / 2008$ & 911,653 & 119,195 & 13 & 792,458 \\
\hline $2008 / 2009$ & $1,054,060$ & 127,082 & 12 & 926,978 \\
\hline
\end{tabular}

Source: Joint Admissions and Matriculations Board (JAMB) records, 2008

The JAMB administers the national university entrance examination and informs universities of applicant's scores. Over the years the overall growth has far exceeded the government's policy guidelines as indicated in Table 2. This suggests the necessity for other forms of alternative higher education like DE to fill the gap, as the conventional higher education system has proved to be insufficient to serve the teeming demand for higher education in Nigeria. Furthermore, the projected figures have more than doubled over the years, leaving a huge gap in the admission process, and a large proportion of applicants scrambling for alternative forms of higher education achievable through various forms of distance education.

Table 2: Enrolment Growth-Policy Norms and rates of increase

\begin{tabular}{|c|c|c|}
\hline Category & NUC Policy Norms & Actual growth rate \\
\hline $1^{\text {st }}$ Generation Universities & $3 \%$ & $9 \%$ \\
\hline $2^{\text {nd }}$ Generation Universities & $10 \%$ & $13 \%$ \\
\hline $3^{\text {rd }}$ Generation Universities & $15 \%$ & $21 \%$ \\
\hline
\end{tabular}

Source: Saint, Hartnett and Strassner (2004) 
It is obvious from table 2 that there is a higher growth rate than was projected. There is definitely a high demand for higher education, judging by the statistics in table 1 which shows progressive over-subscription. DE, through the different modes serves as one of the more convenient gap-fillers. Therefore, DE has served as a boost for educational participation at the tertiary level. The huge yearly unplaced candidates into the traditional university system obviously encourages an influx into DE, where many are then forced to be economical with the truth about their ages in order to bypass the 21-year stipulated age limit for entrants into DE institutions. Thus as Okunade (2011) noted:

'Distance learning is designed for older people, mature students and all sorts who are working; but because of admission problem in Nigeria, it has become an alternative for admission. We now have young boys and girls coming for distance learning, such that we now have more undergraduates than the main university'.

The implication is that the present practice deprives the more deserving and often underprivileged adults who were the original intended candidates of $\mathrm{DE}$ to be able to avail themselves of the educational opportunities. Thus, Pityana's (2004) comment that open distance learning in Africa remains an alternative or complementary mode of learning is debatable, going by the current situation in Nigeria where the intended clientele are not ultimately the ones serviced. Okunade (2011), while agreeing that the university provision in Nigeria is inadequate, further submits - 'the truth is that there are not enough universities in Nigeria per population' - and that the solution is not even to recreate infrastructure or multiply universities as is the current practice); he however also supports DE's ability to provide access to higher education even beyond the country's borders. Aderinoye and Ojokheta (2004) further corroborate Okunade and add that:

'the problem of unsatisfied demand for education versus actual supply of educational services contributed to the acceptance, growth, and implementation of distance education programs in Nigeria as a means to bridge the gap between demand and supply'.

The present clientele of DE in Nigeria are often people who are remedying educational deficiencies due to various reasons. Poverty, family commitments, physical disabilities, living in rural or remote locations have often acted as a barrier to higher education for the deserving adult. DE as a veritable mode of adult education in Nigeria currently fills the gap left by mainstream education in terms of access and flexibility. There are two main categories of DE in Nigeria (with several examples and branches) - the Open University and other mainstream universities that offer programs by distance education, in addition to their conventional programs. Major examples of DE institutions in Nigeria are listed below:

\section{1) The Distance Learning Institute}

The biggest example of a Distance Learning Institute in the country is situated within the University of Lagos with a total population that more than doubles the number of students in the mainstream University; it sets the pace among other Distance Learning Institutes in the country. The higher figure of intake is due to her exemption from the National Universities Commission's (NUC) embargo on over 10\% admission (of the full time figure) policy for Part-Time programs as they are regarded as non-full-time. The University of Lagos Distance Learning Institute DLI started in 1974 as the Correspondence and Open Studies University (COSU); and was the first attempt to establish a DE unit as part of a university. The DLI was founded on part of the objectives stated in the report of the Ashby Commission of 1959 which was to provide facilities for part time studies in different courses through Correspondence and Distance Learning techniques. According to the admission records in the last two years the number of applicants to those registered is higher than that of the mainstream university as shown below in direct comparison to the figures in tables 1 and 2 :

Table 3: Application and admission patterns of DLI

\begin{tabular}{|c|c|c|c|}
\hline Session & Number of applicants & Number registered & Percentage \\
\hline $2008 / 2009$ & 7,000 & 3463 & $49.47 \%$ \\
$2009 / 2010$ & 7,000 & 3155 & $45.07 \%$ \\
$2010 / 2011$ & 7,200 & 2947 & $40.93 \%$ \\
\hline
\end{tabular}

Source: DLI records (2011) 
Tables 1 and 3 show a vast difference in the number of intakes through the ratio of number of candidates registered in the figures in table 3 , which obviously exceeds that of mainstream university in tables 1 and 2 , along with the percentage of intake. This is partly because the non-part-time is allowed a higher intake than in full-time education. Part time programs are currently allowed to admit $10 \%$ of the full time program figure. DLI therefore, as a mode of DE, can be said to help bridge the gap in access to higher education, but it is rather packaged to better suit adult learners.

\section{2) The National Open University of Nigeria}

The National Open University of Nigeria (NOUN) was established in 1983 by an Act of the National Assembly as the first Distance Learning Institution in the country as it became increasingly clear that the traditional means of face-to-face classroom delivery was inadequate to meet the people's demand for higher education, especially with the government's clampdown on the use of satellite campuses. After a few false starts, the NOUN was re-opened in 2002 and has functioned with renewed vigour since. NOUN is on a mission to provide functional cost-effective, flexible and quality education to all those who seek knowledge. This is in addition to providing wider access to education, equity and equality of educational opportunities, in support of EFA goals and lifelong learning as well as convenient education. It has headquarters in Lagos with liaison offices and study centres all over the nation. Its Learner Support Service Unit provides print materials, audio tapes, CD-ROM, Radio and internet service to students in the various study centers and the university presently has over 64,000 students as of June 2011 registered for the different programs in the various schools and 168,634 enrolled. The breakdown is shown in the following table:

Table 4: Record of admitted and registered students of NOUN from 2008 to 2011

\begin{tabular}{|c|c|c|c|}
\hline Year & No admitted & No registered & Percentage \\
\hline $2008 / 2009$ & 33,329 & 13,505 & $40.52 \%$ \\
$2009 / 2010$ & 24,689 & 8,114 & $32.86 \%$ \\
$2010 / 2011$ & 110,616 & 42,514 & $38.43 \%$ \\
Total & $\mathbf{1 6 8 , 6 3 4}$ & $\mathbf{6 4 , 1 3 3}$ & $\mathbf{3 8 . 0 3 \%}$ \\
\hline
\end{tabular}

Source: NOUN records 2011

The above figure indicates the level of interest in the NOUN programs and their admission ratio too is higher, along with a bit more relaxed entrance requirement from the regular school (they accept a pass in the GCE O'levels in two sittings for entry, unlike the regular university requirement of not more than one sitting). However, it is important to note the high attrition rate between those who are offered admission and those who actually registered. This could be partially explained by the lukewarm reception of DE certificates, along with the possible foreign concept of being self directing, and the lack of awareness of the full potential of DE offerings. Many have benefitted from the offering of NOUN, and the more visible example of prominent graduates of the DE system in Nigeria is the one-time Head of State, General Olusegun Obasanjo, who completed his university education through the NOUN. Many of the teachers in the Nigerian educational system today are also products of DE provision. Aderinoye and Ojokheta (2004) further noted that:

'archived records from these distance institutions reveal that Nigeria's teaching and educational system, which clearly faced an acute shortage of teachers during the introduction of the Universal Primary Education program in 1976, and later the Universal Basic Education in 1999, were unquestionably strengthened through the introduction of new teachers produced via Open and Distance Learning modalities'.

There is therefore little doubt that distance education has contributed immensely to development efforts in Nigeria, especially through the production of teachers into the education system. However, this paper has noted that, going by the way distance education is presently being practiced in Nigeria; it is contrarily doing more of replacing, rather than complementing traditional higher educational services. In essence, the non-formal nature of $\mathrm{DE}$ is not allowed to fully flourish. 
One of the main challenges of NOUN is with the conduct of the students. Students are not familiar with DE study pattern requirements and self study habits and so mill around the study centres regularly expecting face-toface contact with their teachers. This is probably because many of them (because of their age) are initial entrants and their orientation, up to that level, has been that of regular school and prepared them for such. There is therefore the need for re-orientation so that they can imbibe the spirit of self study. Thus there may be the need to intensify training to point them in the right direction through short reorientation programs, to acquaint them with the different study habit requirements of DE. Even the teachers in the system may also need training in how to effectively handle DE programs, as different from regular schools. There is also the issue of teacher training to be done specifically to handle DE.

Correspondence Education as a mode of DE is primarily designed to be conducted using the postal system, and in Nigeria, it was initially used to prepare candidates for the General Certificate of Education (GCE). It was a prerequisite for the London Matriculation Examination, arguably the first 'Open University' experience and several notable Nigerians, prior to independence, have over the years availed themselves of the opportunity (while combining it with other pursuits) and later demonstrated its efficacy through their practice. Rapid Results College and Exam Success Correspondence College were examples of correspondence institutions in Nigeria but have all quietly disappeared from the scene.

Correspondence education, practiced in its original format, is currently the least popular of the different forms of DE. It is a dying form that was highly popular in the late 1950s and 60s in Nigeria with many degrees earned through correspondence colleges abroad. Various problems that have stymied the efforts of education by correspondence growth in Nigeria included a poor postal system where prompt and safe delivery of items cannot be guaranteed, especially to the more remote areas. Unfortunately, even more recent improvements made by NIPOST (the national mail carrier) still prove inadequate to ensure an effective two-way communication between distant learners and their institutions. Correspondence is therefore no longer reliant on the physical postage system which was fraught with problems. All correspondence can now be duplicated online, whether they are in the form of books, files, papers to be graded etc, can all be easily exchanged between the learner and resource person who are physically separated, over the web in electronic form.

All the forms of DE mentioned above are gradually moving towards full computerization and the e-learning mode. DE efforts in Nigeria have been supported by international agencies like UNESCO, Commonwealth of Learning (COL) and the British Council among others. DE practice in Nigeria has also benefited from the first distance University in Africa - the University of South Africa (UNISA) which was established in 1873 and has contributed to the emergence of several Distance Education institutions elsewhere in the continent for human resource development. Other modes of distance education in Nigeria include Satellite Campuses of different Universities and other forms of Extension Education Programs for adult learners.

\section{CHALLENGES OF DISTANCE EDUCATION IN NIGERIA.}

Distance Education faces several challenges in Nigeria today. E-learning, which is used to promote DE, according to Islam (1997), includes computer based learning, web-based learning, virtual classroom and digital collaboration, where content is delivered via the internet, intranet/extranet, audio and/or video tapes, satellite TV and CD-ROM, among others. E-learning helps increase access to learning opportunities, especially individualized learning, and is meant to help entrench a global learning culture. The distance between the learner and mentor calls for alternative means of communication, and DE practice therefore relies heavily on ICT use, because the program is run at a distance, access to technology becomes pivotal to the running of a successful DE program. However in Nigeria there are fundamental issues involved.

Unfortunately, up till date, there are still constraints in ICT delivery for reasons of affordability and access, along with the issue of computer illiteracy, cyberphobia, problems with electricity supply and internet access, according to Bakare (2009). NOUN, for example, still relies heavily on the use of print materials and face-to-face teaching because of the listed problems, coupled with the problem of study habits of the students. Other problems 
include inequality of access to technology, high cost of owning a PC and internet connectivity, which continue to plague the potential success of NOUN. E-learning is currently widely used in most developed nations to promote $\mathrm{DE}$ and Nigeria still struggles to meet with the various challenges. There is also the issue of acceptability of degrees earned purely through the e-learning mode in the nation. Up to the present, a clear picture of completers of the program is also yet to be fully established. It is again notable that human beings are essentially social animals and therefore also require some element of physical interaction to make DE successful and enrich the DE experience. Undergoing certificated courses through the internet was not a popular mode until recently and it is currently the fastest growing form of alternative mode of education in Nigeria today. However it is still highly restricted to middle to high class people who can afford it. The form of online education provided, which would be certificated, is limited to few courses and the majority use it to support the selected teaching method in mainstream education. It is a yet to be fully explored territory with huge potentials for all forms of education. ICT is currently more popular in other forms of education, including its use as a support for mainstream education.

Learning in DE is supposed to be at the convenience of the learner's own space and time, as encouraged by DE; however, there is yet to be a full understanding of the workings of DE methods by the majority of DE students. The learners' lack of basic skills for independent studying habits (as their education so far ill-equips them for this) therefore precipitates the learner's reluctance to take responsibility for their own learning and consequently affects the conduct of DE itself - making it more difficult to practice it non-formally. If care is not taken, adult education will continue to be more formalized than the non-formal mode it is supposed to be, especially if the clientele tends to be of the younger generation. Again, the difficulty in measuring the success rate of DE efforts has made it difficult to assess if it has made the appreciable impact on the educational system it is capable of Sustainable development, which basically involves the improvement of the standard of living of the present generation without jeopardizing that of future generation, is attainable through the education of the adult population and DE. If being an adult entails being in full time work, often being isolated or living a long distance to institutions and other setbacks, then there is the danger of not giving these endangered group of people the justice they deserve, along with equity in educational provision. This is more apparent in the Nigerian situation where a cursory look at the population of the DE system will show an obviously younger population to those it was originally intended for, therefore debunking the equity in the access and affecting the practice of adult education itself.

Unfortunately, Nigeria's answer to the teeming population of applicants who are displaced had been to create more private universities for those who cannot afford to go to neighbouring countries or abroad for higher education. DE still offers a cheaper way of achieving learning objectives; however this is making the wrong crowd flood into the DE system. It is clear that the government's inability to service all applicants will logically make the provision of access and equity stated in the NPE rather elusive. If DE is supposed to increase access for adult learners to DE for purposes of inclusion and equity, presently, it is doing a poor job. It is rather depriving the adult populace of their rightful access to higher education and therefore debarring them from fully participating in development efforts. If care is not taken, the practice of adult education will be seriously affected, as even the teachers will have a dilemma on how to approach the learners, whether as adults or adolescents, and this will change the way DE was meant to be practiced.

\section{CONCLUSION}

There is no doubt that education is a tool per excellence for national development. This is because the impact of an education brings about the empowerment, transformation or the permanent and positive change in behavior of the educated as a result of the knowledge, values, attitudes and skills acquired; the educated person is then expected to improve himself, the quality of his life and consequently the society, all of which translate into self growth and national development. Education is therefore an investment and a durable capital asset. DE is a viable adult education tool that can help to achieve sustainability and create a learning society, equipped with lifelong learning skills that will continue to help them find new solutions to their economic, environmental and social challenges. All the modes of DE in Nigeria have great potential for human and national development but care should be taken to ensure that they are practiced properly. The paper confirms that DE remains a powerful means of achieving social justice, equity, and national development; especially to augment mainstream educational provision, and agrees with Jegede (2003); NPE (2004) and Marope (2005) on the potential contribution of DE to national development. The paper has explored the provision and practice of DE in Nigeria, and, while accepting the efficacy of higher education for economic growth, highlighted some faults and suggested solutions to optimize its potentials. 
Summarily, the paper discovered that certain elements are responsible for the less than popular status of DE in Nigeria, enumerated these and finally advocated for more awareness to the ideal DE situation, among others.

\section{THE WAY FORWARD}

The success of DE in Nigeria is contingent on the cooperation of government through adequate funding and favourable policies and implementation; also to tackle problems of lack of electricity to support the use of technological tools. If $\mathrm{DE}$ is going to fulfil the objective it was originally meant for, there is the need to strengthen its base and widen its reach and ultimately make way for DE to be practiced in Nigeria the way it is practiced globally - in a more non-formal mode. It is advocated that admission policies into regular higher education be strengthened to favour the accommodation of more intakes, and stem the rush into DE; other suggestions are:

- It has become even more important to enlighten the general public and other stakeholders on the potential of DE as an alternative mode of enhancing access to higher education and encourage human development. There needs to be more awareness campaigns to stimulate the interest and promote enrolment of the desired candidates - adults, into DE programs through demonstrations, campaigns and a friendlier and more considerate admission and registration process;

- $\quad$ There is presently a poor perception of DE as inferior to the conventional provision as indicated by its unpopularity as a choice for an alternative by students (who still prefer the conventional mode, given a choice), and of employers preferring certificates from conventional education over DE certificates. Rather, there should be more appreciation of the certificates because the recipients are usually already workers who have real life experience and can make more and immediate contribution to development, hence the need for more awareness to the efficacy of DE;

- $\quad$ Quality assurance must be built in to the DE process throughout to ensure best practice and especially in the quality and training of the distance educators to equip them to better handle DE requirements. The checks and balances instituted will also give more credence and acceptance to DE certificates if there is the assurance that it is operating at the same standard with the regular counterpart;

- $\quad$ There should be a strengthening of the current infrastructural provision for DE and funding, while ensuring that access is given to mature students; this will also mean that the access to traditional higher education must be strengthened to cater for the younger applicants;

- More attention should also be paid to curriculum content at all levels in the educational system to focus on environmental, civic and economic literacy to engender the spirit of sustainability;

- $\quad$ DE students need a re-orientation training, as their mode of education to the present only equips them for face to face learning, and they seem to find it difficult to handle an educational mode that does not include full or face-to face contact. They therefore need a reorientation to prepare them for independent learning. This also implies that there must be re-training for the facilitators in DE programs so that they will not continue to use the regular mode of teaching, but get familiar with DE methods. The more prevalent mode of teaching currently in most tertiary institutions in Nigeria is the traditional face to face, using the Lecture methods and printed material for teaching. In order for us to advance and conform to the digital age, there is the growing need to train teachers as well as the students and encourage that all tertiary institutions be ICT compliant by instituting and implementing relevant policies and enforcing their implementation with the right amount of financial and administrative support, and

- There is indeed the urgent need to encourage the acceptance of ICT as the driving force of DE and make enough provision for it along with the necessary training that will ease the students into this learning mode.

When DE is properly conceptualized and implemented, it has great potential for increasing flexibility of educational provision, lifelong educational opportunities for experienced adults and women. It is also supposed to be more cost effective because of the need for fewer support infrastructures. This makes it even more suitable for developing countries, with rural communities, who need proximity to, as well as affordable education. DE remains one of the strongholds of adult education, and if the non-formal element is eroded, it will become mere glorified formal education instead of retaining the flexibility that is the essence of DE practice. DE must be conducted in the conventional way in order to retain its strength and appeal. We must continue to appreciate the enormous potential of DE for sustainable national growth. More than anything, there is the need to pay more attention to learning by technology media and provide the necessary environment for it to flourish as this is the way of the future. 


\section{AUTHOR INFORMATION}

T.V. Bakare, Ph.D., Department of Adult Education, University of Lagos, Nigeria, E-mail: tbakare@ unilag.edu.ng. This paper was presented at the 2012 Orlando International Academic Conference, Orlando, Florida. January 2-4, 2012

\section{REFERENCES}

1. ADEA (2002). Open and distance learning in Sub-Saharan Africa. Working Group on Distance Education and Open Learning. Réduit: Author.

2. Aderinoye, Rashid \& Kester Ojokheta (2004). 'Open-Distance Education as a mechanism for sustainable development: reflection on the Nigerian experience'. International review of research in open and distance learning. 5(1).

3. Amuako, Bruce (2009). Adult education, tool for national development. Speech by the non-formal education division of the Ministry of Education (NFED) Municipal Director in an interview with the Ghana News Agency. The Peace FM online forum. www.peacefmonline.com retrieved 30 $0^{\text {th }}$ November, 2011.

4. Bakare, T.V. (2009) E-learning in the University environment: the Nigerian experience. Paper presented at the IATED Conference, Barcelona, Spain. 8-11 ${ }^{\text {th }}$ July.

5. Boshier, Roger (2002), "Farm-gate intellectuals, excellence and university problem in Aotearoa/New Zealand", Studies in Continuing Education, 24 (1,) Pp. 5 - 24.

6. COL (2005). Distance Education and Open Learning in Sub-Saharan Africa: criteria and conditions for quality and critical success factor. The Working Group on Distance Education and Open Learning: A survey of Policy and Practice. The Commonwealth of Learning Final Report. January.

7. Federal Republic of Nigeria (2004). National policy in education $\left(4^{\text {th }}\right.$ ed.). Lagos: NERDC Press.

8. Islam,M.T (1997). 'Educational Technology for 21st century'. The Observer Magazine. Dhaka, May 9. Pp $3-4$.

9. Jegede, O. (2003). Taking the distance out of higher education in 21st century Nigeria. Paper Presented at the Federal Polytechnic, Oko, Anambra state on the occasion of the Convocation ceremony and $10^{\text {th }}$ Anniversary celebration held on Friday, 28. Pp 61-70

10. Jensen, Linda (1998). Adult learning theory: implications for Distance Education. Arizona State University, Summer. EMC.

11. Kaufman, R., Watkins, R., and Guerra, I. (2001). 'The future of Distance Education: Defining and sustaining useful results’. Educational Technology Magazine. 41(3); Pp 19-26.

12. Knowles, Malcolm (1984).

13. Marope, Mmantsetsa Toka (2005). Namibia human capital and knowledge development for economic growth with equity, Africa Region Human Development Working Paper Series - No. 84: The World Bank.

14. Moodley, Sivalingum (2002). Inclusive education: challenges for distance learning, policy and practice. Pathways 6 Conference. Johannesburg: Technikon, SA.

15. National Population Commission (2007). Federal republic of Nigeria official gazette no 4:94. Legal Notice on Population of the 2006 Census Report.

16. Nekongo-Nielsen, Haaveshe Centre for external studies (2011). The contributions of open and distance learning to national development in Namibia. http://pcf4.dec.uwi.edu/viewpaper Retrieved 1/12/2011

17. Oduwaiye, Rhoda O (2011). Access and Equity in Nigerian Universities: Challenges and the way forward. http://www.unilorin.edu.ng/ejournals/index.php/ijem/article/viewFile/129/47. Retrieved 19 ${ }^{\text {th }}$ Dec. 2011. pp $65-74$

18. Okunade, Bayo (2011). Open distance learning, a viable option to varsity education. The Director, Distance learning Centre, University of Ibadan. Interview by Segun Olugbile on General NBF Topic, Education. www.nigeriabestforum.com retrieved $7^{\text {th }}$ December, 2011.

19. Omolewa, Michael (2001). The challenges of education in Nigeria. Ibadan: University of Ibadan Press.

20. Pityana, Barney (2004). Open distance learning in Africa: access, quality, success. Pretoria: University of South Africa. January 30 $0^{\text {th. }}$ www.unisa.ac.za/contents/odl_africa. Retrieved $6^{\text {th }}$ December, 2011.

21. Saint, W.; Hartnett, T. A. and Strassner, E. (2004). 'Higher Education in Nigeria: A Status Report'. World Education News and Reviews.

22. Salmon, G. (2000). E-Moderating: the key to teaching and learning online. London: Kogan Page 
23. Ukertor, Gabriel Moti (2010). 'The challenges of access to university education in Nigeria'. DSM Business Review; 2 ( 2) December. Pp 27 - 56.

24. UNESCO (2002). Open and distance learning; Trends, Policy and Strategy consideration. Paris, UNESCO. 